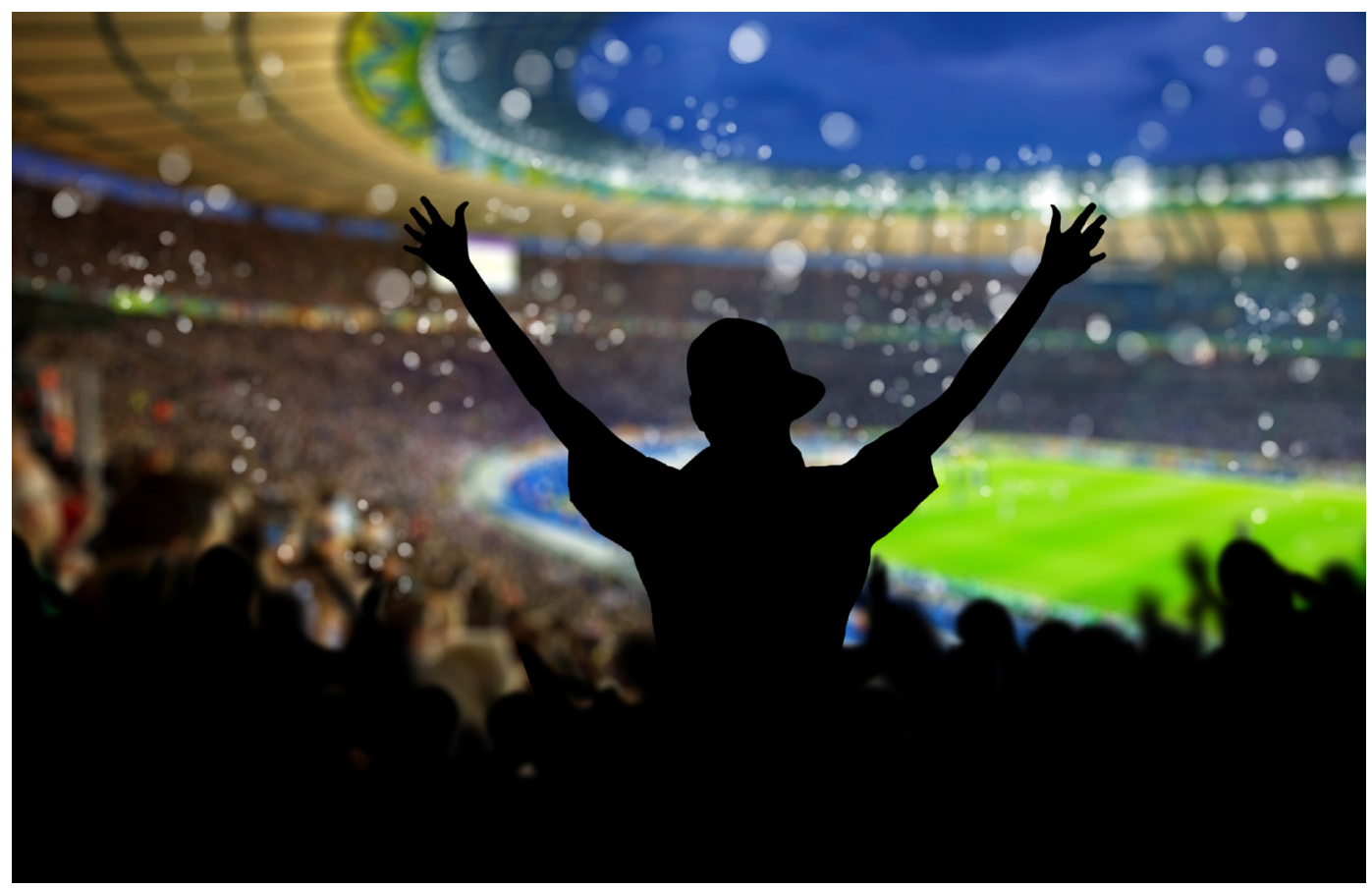

\title{
Rejecting the Uncertainty of Outcome Hypothesis on Attendance Demand in all Four Major European Football Leagues
}

\author{
NICK DAMGAARD JESPERSEN \& LINE BJØRNSKOV PEDERSEN
}

Keywords: Uncertainty of Outcome, attendance demand, betting odds, tobit estimation, European football

The uncertainty of outcome (UO) hypothesis, stating that spectators prefer matches with uncertain outcomes, has over the years been tested across different sports and countries yielding different conclusions. In the case of European football, results are mixed, perhaps due to variation in the use of UO measures, explanatory variables, seasons and econometric models. We test the UO hypothesis on the four major European football leagues using the same variables, seasons and econometric models across leagues. The results show that the UO hypothesis is rejected in all four leagues. Moreover, attendees in the the Spanish La Liga and the Italian Serie A prefer matchers with lower levels of uncertainty. This is to date the most compelling evidence that the UO hypothesis on attendance demand does not hold in European football. 


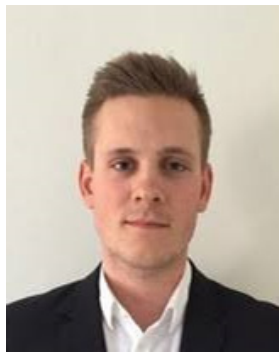

NICK DAMGAARD JESPERSEN

Cand.Oecon. (Msc.Economics) from University of Southern Denmark, Faculty of Business and Social Sciences

nickdamgaard@hotmail.com

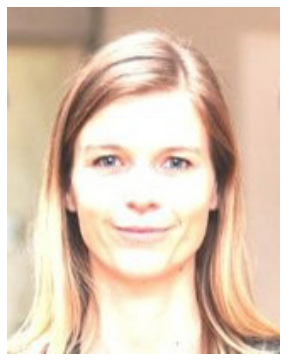

\section{LINE BJØRNSKOV PEDERSEN}

Associate professor, Senior researcher

DaCHE \& FEA, University og Southern Denmark

lib@sdu.dk

\section{INTRODUCTION}

“'Oh Lord make us good, but not that good', must be their prayer" (Neale, 1964). This famous quote refers to professional sports clubs and their view on the competition between teams in a league. Neale argues that the clubs need opponents of a certain quality in order to attract spectators to their matches and to sustain the general interest. It is the competition and uncertainty of outcome that drives fans' interest towards an event. The term "uncertainty of outcome" (UO) is typically attributed to Rottenberg (1956), who pointed out that "uncertainty of outcome is necessary if the consumer is to be willing to pay admission to the game". The UO hypothesis has since been discussed innumerable times and traditionally, there has been a consensus that UO is important to attendance demand (see e.g. Borland and McDonald, 2003; Szymanski, 2003 and Pawlowski, 2013 for an overview of the literature), although recent theoretical evidence shows that this may not always be the case (Coates et al., 2014). Also, empirical evidence from European leagues has so far been mixed with regards to whether increased UO leads to increased attendance demand.

Falter and Perignon (2000) investigated French football and concluded that increased UO had a positive effect on demand. So did Garcia and Rodriguez (2002) in their investigation of Spanish football, and Forrest and Simmons (2002) in their study of English football. Czarnitzki and Stadtmann (2002), however, found that increased UO had no effect on demand in German football, and so did Forrest and 
Simmons (2006) as well as Buraimo (2008) in English football, and Pawlowski and Nalbantis (2015) in the Austrian and Swiss football leagues. Buraimo and Simmons (2008) found that increased UO had a negative effect on demand for English football, hereby rejecting the UO hypothesis, and Pawlowski and Anders (2012) came to the same conclusion in their study of German football, as did Martins and Cró (2018) in their study of Portuguese football.

As existing studies use different UO measures, different explanatory variables collected from different seasons and analyzed with different econometric models, it complicates a direct comparison and renders it difficult to draw a decisive conclusion on the credibility of the UO hypothesis on attendance demand for the case of European Football. The objective of this paper is to test the UO hypothesis on attendance demand in a comparative analysis of the four major European football leagues: the English Premier League, the Spanish La Liga, the German Bundesliga and the Italian Serie A. The English, Spanish and Italian leagues all have 20 teams, while the German league has 18. In all leagues, all teams face each other home and away. In England, Spain and Italy the three lowest placed teams at the end of the season are relegated and replaced by the three best teams from the league below. In Germany, the two lowest placed teams are relegated directly and replaced by the two best teams from the league below. Number 16 in the Bundesliga (the third lowest placed team) faces number 3 from the league below in two play-off matches to decide who gets to play in the Bundesliga in the coming season. Data is investigated for seasons 2009/10, 2010/11 and 2011/12 using Theil's measure of uncertainty as a UO estimate. The capacity constraints of stadiums lead to right-censored data, and tobit-regressions are used to resolve this issue in the estimation. The study adds to the current knowledge on UO effects on attendance demand in European Football by consistently exploring the UO hypothesis across leagues using the same econometric methods, explanatory variables and measure of uncertainty.

The remainder of the article is structured as follows. In the next section, we briefly revisit the UO hypothesis and describe our model specification, econometric estimation strategy and data collection. In the third section the results are presented. The fourth section includes a discussion on results and limitations. The fifth section concludes the article. 


\section{METHOD AND DATA}

\section{The uo hypothesis revisited}

According to the UO hypothesis (Rottenberg, 1956; Neale, 1964), we would expect spectators to have the highest demand for matches in which teams possess equal abilities, i.e. match outcome is highly uncertain. Szymanski (2003) distinguishes between three different forms of uncertainty: match uncertainty, seasonal uncertainty and championship uncertainty. Match uncertainty refers to the uncertainty of outcome of individual matches and is the focus of this article. Seasonal uncertainty refers to the uncertainty of the winner of a single season (Cairns et al.,1986). Borland and Macdonald (2003) note that there is strong evidence of an effect of seasonal uncertainty on demand in sports in general. Finally, championship uncertainty, or long-term uncertainty, measures team dominance in a league over several seasons. Evidence of long-term uncertainty has not been studied as much as the other two types of uncertainty, but according to Borland and Macdonald (2003) some studies find support for a positive relationship between long-term uncertainty and attendance.

Recently, Coates et al. (2014) have presented a new angle to uncertainty of outcome, where they develop a consumer choice model of the decision to attend sporting events that include both uncertainty and reference-dependent preferences. Their model shows that the existence of the UO hypothesis depends on the marginal utility of wins and losses. The UO hypothesis only holds when the marginal

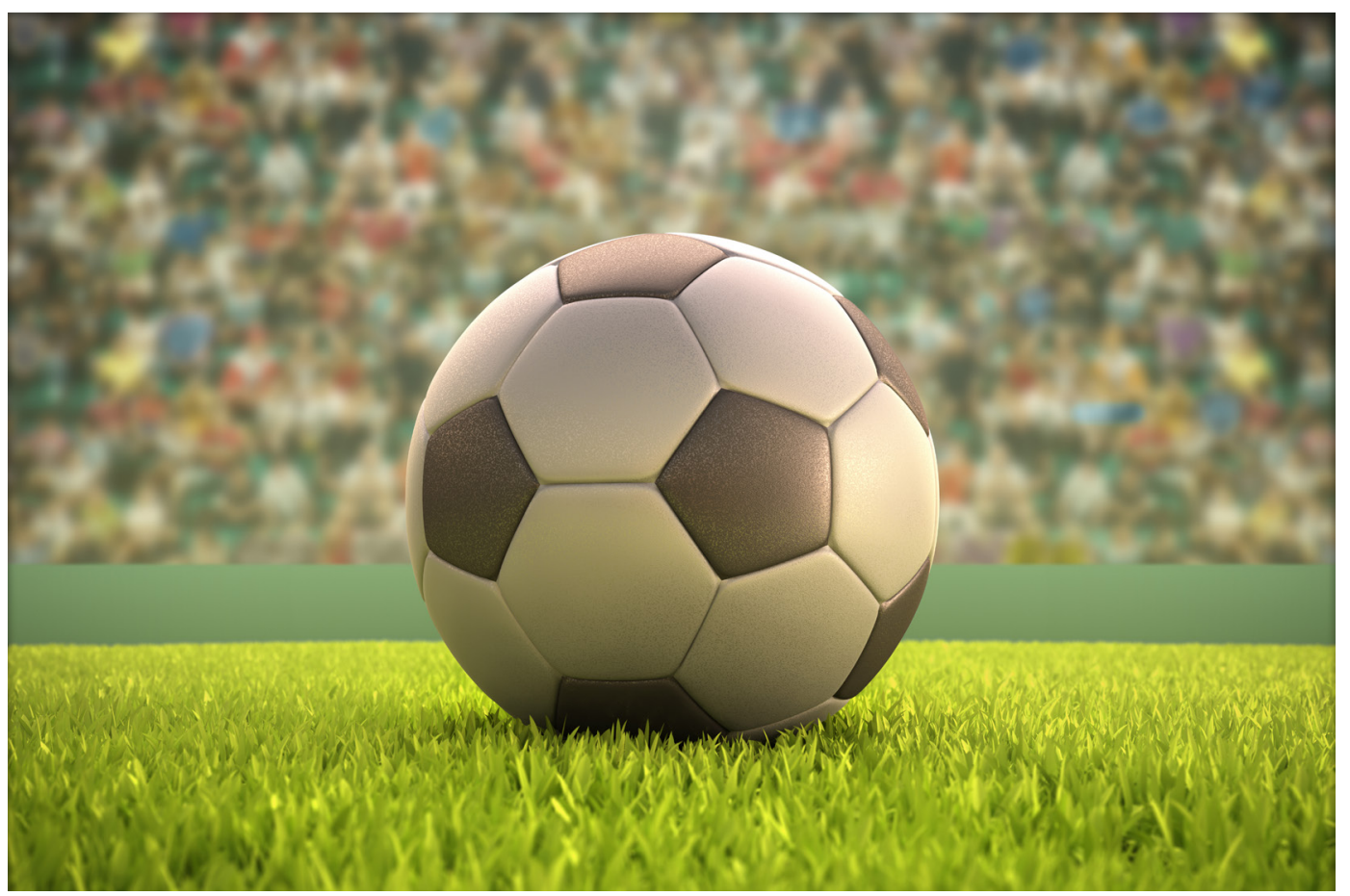


utility generated by an unexpected win exceeds (or equals) the marginal utility of an unexpected loss. When the marginal utility of an unexpected loss exceeds the marginal utility of an unexpected win (loss aversion) - a situation that can be motivated by prospect theory (Kahneman and Tversky, 1979) - the UO hypothesis does not hold, and demand increases when uncertainty is low. Whether demand increases or decreases with an increase in uncertainty is what is tested in this study. Coates et al. (2014) review past research and conclude that there is evidence supporting the reference-dependent model with loss aversion. Martins and Cró (2018) also find support of this model in their study of Portuguese football.

\section{Model specification and variables}

Our model controls for various factors including weekend, the distance between the two clubs, whether the game is a derby, the teams' reputation, whether the game is the home team's first or last home game of the season and team's league standings. We estimate attendance demand by the following function:

$$
\ln (\text { attendance })=F(\text { weekend }, \text { distance }, \text { derby, home team reputation, }
$$

away team reputation, home team's first home game, home team's last home game,

home team's league standing, away team's league standing,

Theil's measure of uncertainty)

In the model, weekend indicates that the game was played on either a Saturday or Sunday relative to on a weekday (Monday - Friday). Traditionally football games have been played in the weekend (Saturday or Sunday), but along with an increasing number of televised games and a tighter schedule, a fair amount of games are also played on weekdays. We expect higher demand for weekend games, since most people have the day of. Forrest and Simmons (2006) find evidence of a negative effect on attendance from games played midweek. So does Garcia and Rodriguez (2002).

The distance between the two involved clubs is the driving distance between the clubs' stadiums measured in kilometres. Distance is calculated using Google's route planner (www.maps.google.com). We hypothesise that greater distances will result in lower demand, since the supporters of the away team will have to spend more time and money attending the games, and since the rivalry of two teams is usually bigger if they are in close geographical proximity (even if the game is not defined 
as a derby). Garcia and Rodriguez (2002) and Buraimo and Simmons (2008) both find a negative effect of distance on attendance.

The variable derby indicates whether the game is a derby or not. Most derbies are characterised by involving teams from the same city, but it is not always the case (neither are all games between two teams from the same city a derby). The definition of a derby is vastly a subjective judgement, and in this study, we have used the website www.eurorivals.net/derbies to define the derbies. This website also includes matches traditionally referred to as rivalries (e.g. Real Madrid vs. FC Barcelona in Spain and Arsenal vs. Manchester United in England). In previous literature (e.g. Buraimo and Simmons, 2008; Martins and Cró, 2018) this variable is almost always significant and positive in relation to attendance demand, and we expect the same.

The affiliation between clubs and their supporters is captured with the variables home team reputation and away team reputation. A team's reputation does not only depend on the results of a couple of games or the outcome of a single season, but also on it's ending position in former years. We use the same measure for reputation (REP) as Czarnitzki and Stadtmann (2002). REP is estimated as:

$$
R E P=\sum_{t=1}^{T} \frac{n}{x_{t} \sqrt{t}}, \text { with } T=10
$$

$x_{t}$ is the team's ending position in the league $t$ years ago and $n$ is the number of teams in the league. The index is constructed to reflect the decreasing effect of time on a team's reputation by weighing the position over the number of years since the position was obtained. The index will result in higher values for successful teams and vice versa. We expect the variable to be positive and significant across leagues in line with Czarnitzki and Stadtmann (2002).

As the names indicate, home team's first home game and home team's last home game tell whether a game is the first or last home game in the season. These variables are included to capture some of the effects a season start/ending might have on supporters. At the start of a season, the teams start fresh after a three-month break from competition, so with supporters eagerly awaiting the new season it is likely that there will be a peak in attendance at the first game. By the end of a season supporters face three months without games and might thus be willing to go the extra mile to attend the last home game. Following these assumptions, we expect a 
positive sign on both variables.

Home team's league standing and away team's league standing indicate the two teams' positions before the match. These variables are included to capture the effects of the teams' performances. Alternate performance measures have been used by Buraimo and Simmons (2008), Forrest and Simmons (2002), Pawlowski and Nalbantis (2015) and Martins and Cró (2018), where they find a positive effect from performance on attendance. Based on these findings, we expect the number of attendees to increase the higher the position of the teams.

Finally, the UO is measured by the Theil estimate, where betting odds are transformed into probabilities by taking the inverse of the odds and adjusting for the bookmakers' profit margin. Using Theil's measure of uncertainty (Czarnitzki and Stadtmann, 2002; Buraimo and Simmons, 2008) makes it possible to incorporate the probabilities of all three outcomes of a game. Theil's measure is defined as:

$$
\text { Theil }=\sum_{i=1}^{3} \frac{p_{i}}{\sum_{i=1}^{3} p_{i}} \ln \left(\frac{\sum_{i=1}^{3} p_{i}}{p_{i}}\right)
$$

$p_{i}$ denotes the probability of a home team win, a draw and an away team win, respectively. Since a high value of Theil's measure indicates high uncertainty, a positive sign on this would be expected if the UO hypothesis holds true. However, as mixed results have been obtained in earlier studies on European football we have no clear expectation as to the sign of the variable.

Other explanatory variables, such as weather conditions at the beginning of the game, whether the game was televised live and ticket prices, could also have been included in the model (see e.g. Garcia and Rodriguez, 2002; Martins and Cró, 2018). How such additional explanatory variables would impact the model is discussed in the discussion section.

\section{Econometric model}

Attendance figures are used as proxy for attendance demand. However, in some cases games are sold out and the attendance figure will therefore not necessarily capture the true demand of the game. In such a case, data is right censored with the stadium capacity as the censoring point. In line with Buraimo and Simmons (2008), a game is defined as sold out if attendance makes up at least $95 \%$ of stadium capacity. In our data 590 observations (52\%) from the English Premier League are right censored, 554 (60\%) in the German Bundesliga, 43 (4\%) in the Italian 
Serie A and 102 (9\%) in the Spanish La Liga.

Due to censoring, a tobit model is used for estimation. The relevant statistical distribution of attendance demand is a mixture of discrete and continuous distributions representing probabilities of a sold out game and attendance figures for the games not sold out. We use a random effects model that includes a set of team-specific constant terms, which are randomly distributed across teams. In such a model, it is assumed that the variation across teams is uncorrelated with the independent variables (Greene, 1997; Buraimo and Simmons, 2008). The specified model is run separately across each of the four leagues. Data processing is executed in STATA 12 using the command xttobit.

\section{Data collection}

Betting odds from Bet365 are taken from the internet database http://www.football-data.co.uk/, where data on all four leagues are available. For weekend games, odds are collected Friday afternoons and on Tuesday afternoons for midweek games. We note that three matches from the Italian Serie A have no available odds and are therefore removed from our data set.

Attendance data are gathered primarily from the internet site http://www.soccerstats.com/ supplemented with the site http://www.transfermarkt.co.uk/. It has not been possible to find attendance data for Genoa's last two home games in the 2011/2012 season in the Italian Serie A, and these are thus deleted from the data set. Descriptive statistics are shown in table 1.

Table 1. Descriptive statistics

\begin{tabular}{|l|l|l|l|l|}
\hline \multicolumn{1}{|c|}{ Variable } & Mean & Std. dev. & Minimum & Maximum \\
\hline Attendance & & & & \\
\hline England & 34675.69 & 14396.15 & 14042 & 75627 \\
\hline Germany & 43340.21 & 15923.85 & 16225 & 80270 \\
\hline Italy & 23908.99 & 14509.85 & 1109 & 80000 \\
\hline Spain & 27918.58 & 19202.31 & 2200 & 99252 \\
\hline In(Attendance) & 10.38 & & & 11.24 \\
\hline England & 10.61 & 0.39 & 9.54 & 11.30 \\
\hline Germany & 9.91 & 0.37 & 9.69 & 11.29 \\
\hline Italy & 10.05 & 0.59 & 7.01 & 11.51 \\
\hline Spain & & 0.59 & 7.70 & \\
\hline
\end{tabular}




\begin{tabular}{|c|c|c|c|c|}
\hline \multicolumn{5}{|l|}{ Weekend } \\
\hline England & 0.79 & 0.41 & 0 & 1 \\
\hline Germany & 0.89 & 0.32 & 0 & 1 \\
\hline Italy & 0.83 & 0.38 & 0 & 1 \\
\hline Spain & 0.84 & 0.37 & 0 & 1 \\
\hline
\end{tabular}

Distance

\begin{tabular}{|l|l|l|l|l|}
\hline England & 216.06 & 133.52 & 1.30 & 579.20 \\
\hline Germany & 366.88 & 184.64 & 7.30 & 802.00 \\
\hline Italy & 594.57 & 397.74 & 0.00 & 1596.00 \\
\hline Spain & 613.84 & 392.27 & 3.10 & 2497.00 \\
\hline
\end{tabular}

Derby

\begin{tabular}{|l|l|l|l|l|}
\hline England & 0.05 & 0.21 & 0 & 1 \\
\hline Germany & 0.02 & 0.12 & 0 & 1 \\
\hline Italy & 0.02 & 0.16 & 0 & 1 \\
\hline Spain & 0.02 & 0.14 & 0 & 1 \\
\hline
\end{tabular}

Home team REP

\begin{tabular}{|l|c|c|c|c|}
\hline England & 15.95 & 19.62 & 0 & 79.30 \\
\hline Germany & 15.88 & 15.46 & 0 & 69.86 \\
\hline Italy & 15.94 & 18.22 & 0 & 77.63 \\
\hline Spain & 16.07 & 18.51 & 0 & 75.45 \\
\hline
\end{tabular}

Away team REP

\begin{tabular}{|l|c|c|c|c|}
\hline England & 15.95 & 19.62 & 0 & 79.30 \\
\hline Germany & 15.88 & 15.46 & 0 & 69.86 \\
\hline Italy & 15.94 & 18.22 & 0 & 77.63 \\
\hline Spain & 16.07 & 18.51 & 0 & 75.45 \\
\hline
\end{tabular}

Home team's first home game

\begin{tabular}{|l|c|c|c|c|}
\hline England & 0.05 & 0.22 & 0 & 1 \\
\hline Germany & 0.06 & 0.24 & 0 & 1 \\
\hline Italy & 0.05 & 0.22 & 0 & 1 \\
\hline Spain & 0.05 & 0.22 & 0 & 1 \\
\hline
\end{tabular}




\begin{tabular}{|c|c|c|c|c|}
\hline \multicolumn{5}{|c|}{ Home team's last home game } \\
\hline England & 0.05 & 0.22 & 0 & 1 \\
\hline Germany & 0.06 & 0.24 & 0 & 1 \\
\hline Italy & 0.05 & 0.22 & 0 & 1 \\
\hline Spain & 0.05 & 0.22 & 0 & 1 \\
\hline \multicolumn{5}{|c|}{ Home team's league standing } \\
\hline England & 10.66 & 5.95 & 1 & 20 \\
\hline Germany & 9.58 & 5.29 & 1 & 18 \\
\hline Italy & 10.60 & 5.89 & 1 & 20 \\
\hline Spain & 10.66 & 5.97 & 1 & 20 \\
\hline \multicolumn{5}{|c|}{ Away team's league standing } \\
\hline England & 10.29 & 5.85 & 1 & 20 \\
\hline Germany & 9.32 & 5.24 & 1 & 18 \\
\hline Italy & 10.21 & 5.82 & 1 & 20 \\
\hline Spain & 10.26 & 5.82 & 1 & 20 \\
\hline \multicolumn{5}{|c|}{ Theil's measure } \\
\hline England & 0.97 & 0.14 & 0.48 & 1.10 \\
\hline Germany & 1.00 & 0.11 & 0.54 & 1.10 \\
\hline Italy & 1.01 & 0.10 & 0.49 & 1.10 \\
\hline Spain & 0.97 & 0.16 & 0.38 & 1.10 \\
\hline
\end{tabular}

The English Premier League, the Spanish La Liga and the Italian Serie A play 380 games per league per season. We study three seasons resulting in 1140 observations for each of the three countries (1135 observations from the Italian Serie A due to deletion of five games). The German Bundesliga plays 306 games per season. For three seasons, we get 918 observations from this league. 


\section{RESULTS}

Table 2 shows results for the random effects tobit models for all four leagues.

The weekend variable shows that playing on a weekend compared to during the week significantly increases attendance in England and Spain, but the effect is insignificant for Germany and Italy. The distance between the two clubs' stadiums is negative in all four leagues but insignificant for the Italian Serie A and the Spanish La Liga. The signs on derby confirm that rivalry has a strong influence on attendance demand, and the coefficient is only insignificant in the German Bundesliga. A reason for the difference between the German league and the rest might be that the German Bundesliga has the highest fraction of sold out matches of all leagues and only $2 \%$ of the German games are considered derbies. In all four leagues, the sign on away team reputation is positive and significant, while the sign on home team reputation is positive and significant only in the Spanish La Liga. Assuming the majority of spectators being supporters of the home team, they seemingly prefer watching games against opponents with successful historical results. Buraimo (2008) argues that fans get used to the level of local talent and are therefore more sensitive to variations in the away team's level of talent (i.e. away team reputation). Home team's first home game has a significantly negative effect on attendance in the English Premier League, while home team's last home game has a significantly positive impact on attendance demand in the English Premier League and the German Bundesliga. Home team's league standing is significant and negative for all four leagues meaning that performing well in the league increases attendance demand. Away team's league standing has the same sign but is only significant in the English and Spanish leagues.

The sign of our Theil uncertainty measure is negative for all four leagues, but insignificant for the English Premier League and the German Bundesliga (although the latter is significant at the $10 \%$ significance level). Thus, in these two leagues, uncertainty of outcome, ceretis paribus, has no effect on attendance demand, while increasing UO in Italy and Spain results in lower demand. Thus, the OU hypothesis is rejected across all four major European football leagues. 


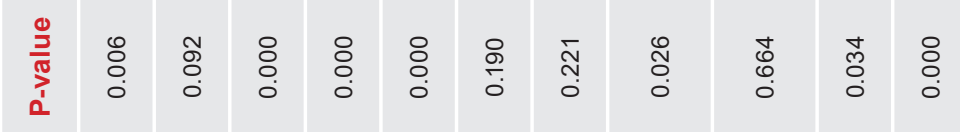

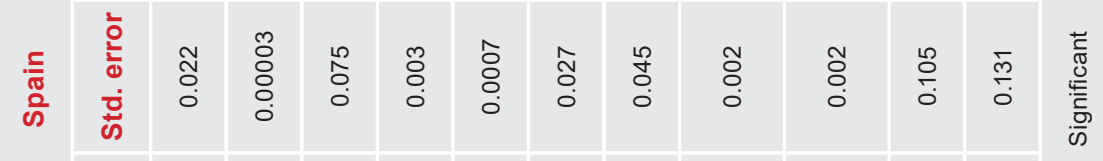

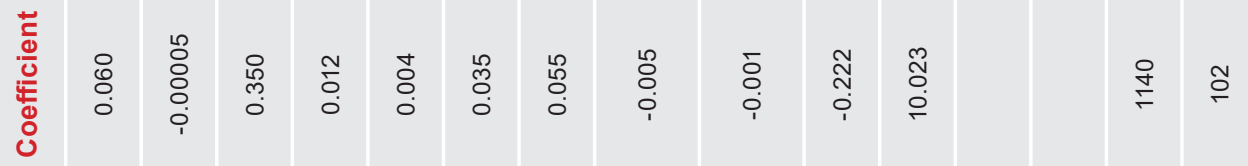

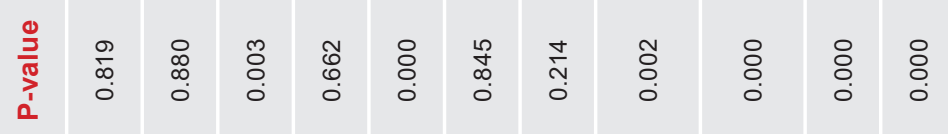

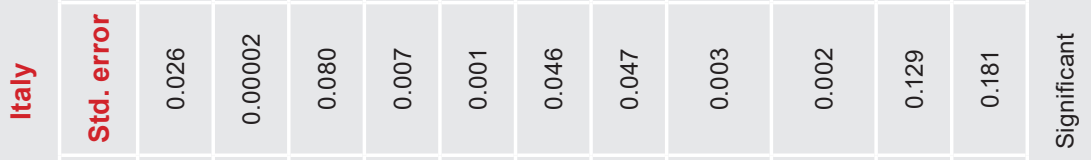

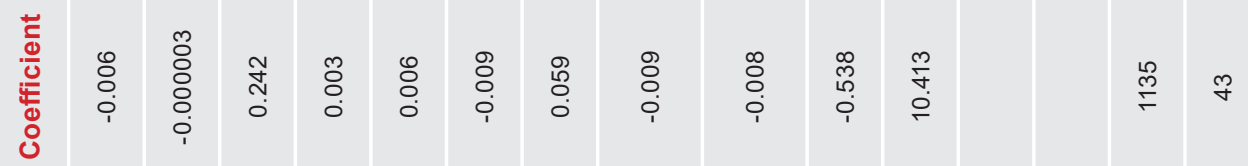

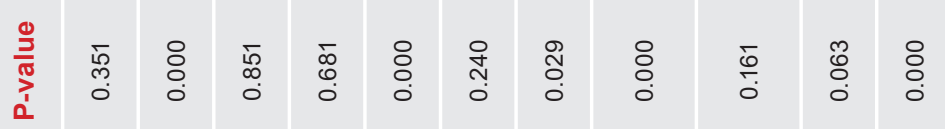

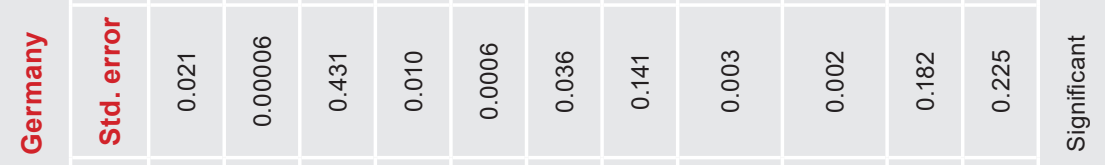

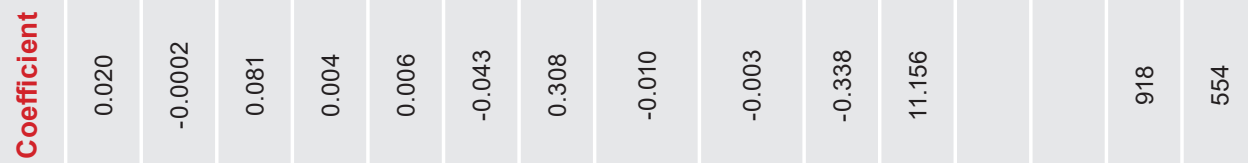

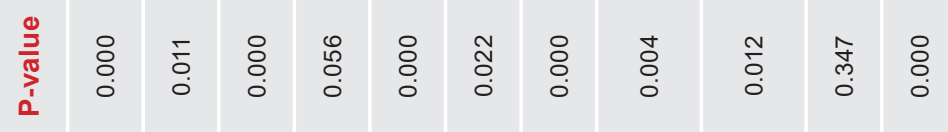

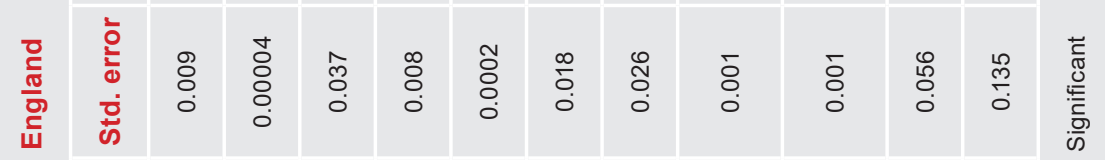

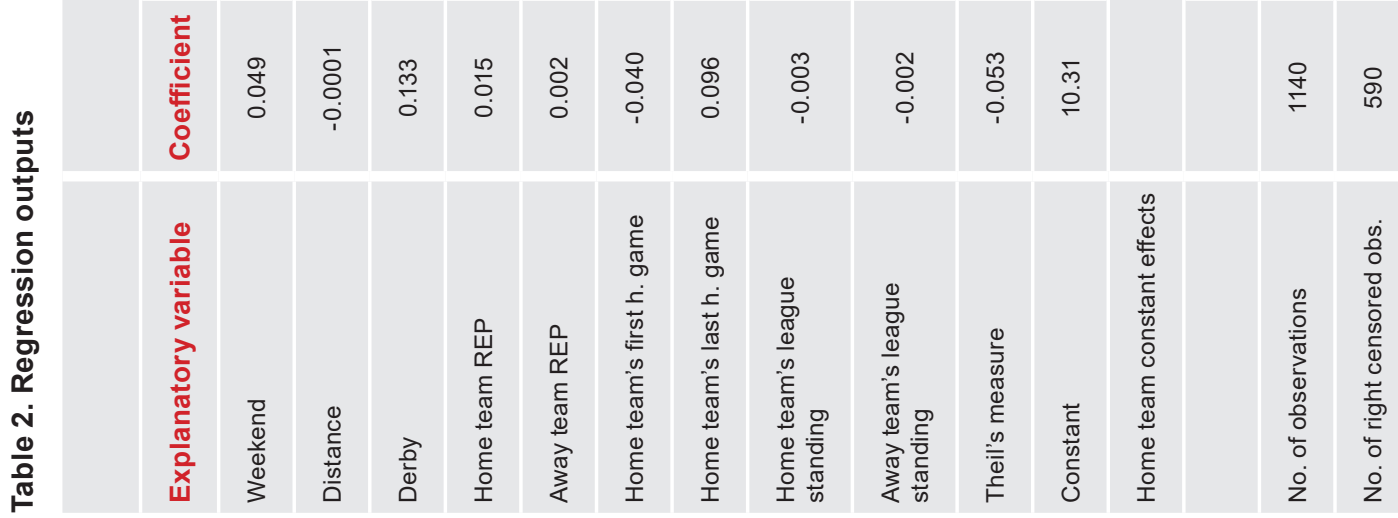




\section{DISCUSSION}

This study rejects the UO hypothesis in all four major European football leagues. So why does increasing UO result in lower or unchanged attendance demand in the four major European leagues? As mentioned, it seems reasonable to assume that the majority of spectators at a football game support the home team and thus have strong affiliations with the club. As also suggested by Buraimo and Simmons (2008), these supporters presumably have very strong preferences for home team victories, thereby wishing for a high probability of a home team win (leading to low UO). However, Pawlowski and Anders (2012) showed in their study of German football that attendance increased when the away team was the superior team, rather than when the home team was a strong favourite. This suggests that, aside from the effect of the brand value of the visiting team, fans may attend the stadium to support their team when they are facing a strong opponent. Furthermore, the teams in the European football leagues are not just fighting for the championship, as the best placed clubs by the end of a season will be playing in intercontinental tournaments (Champions League and Europa League) the following season. Both tournaments are highly prestigious and have high impact on clubs' economies, so the opportunity to play these may also explain the strong preference for home team wins. This was confirmed in the paper by Pawlowski and Anders (2012), where attendance in German football was shown to increase when the teams still had a

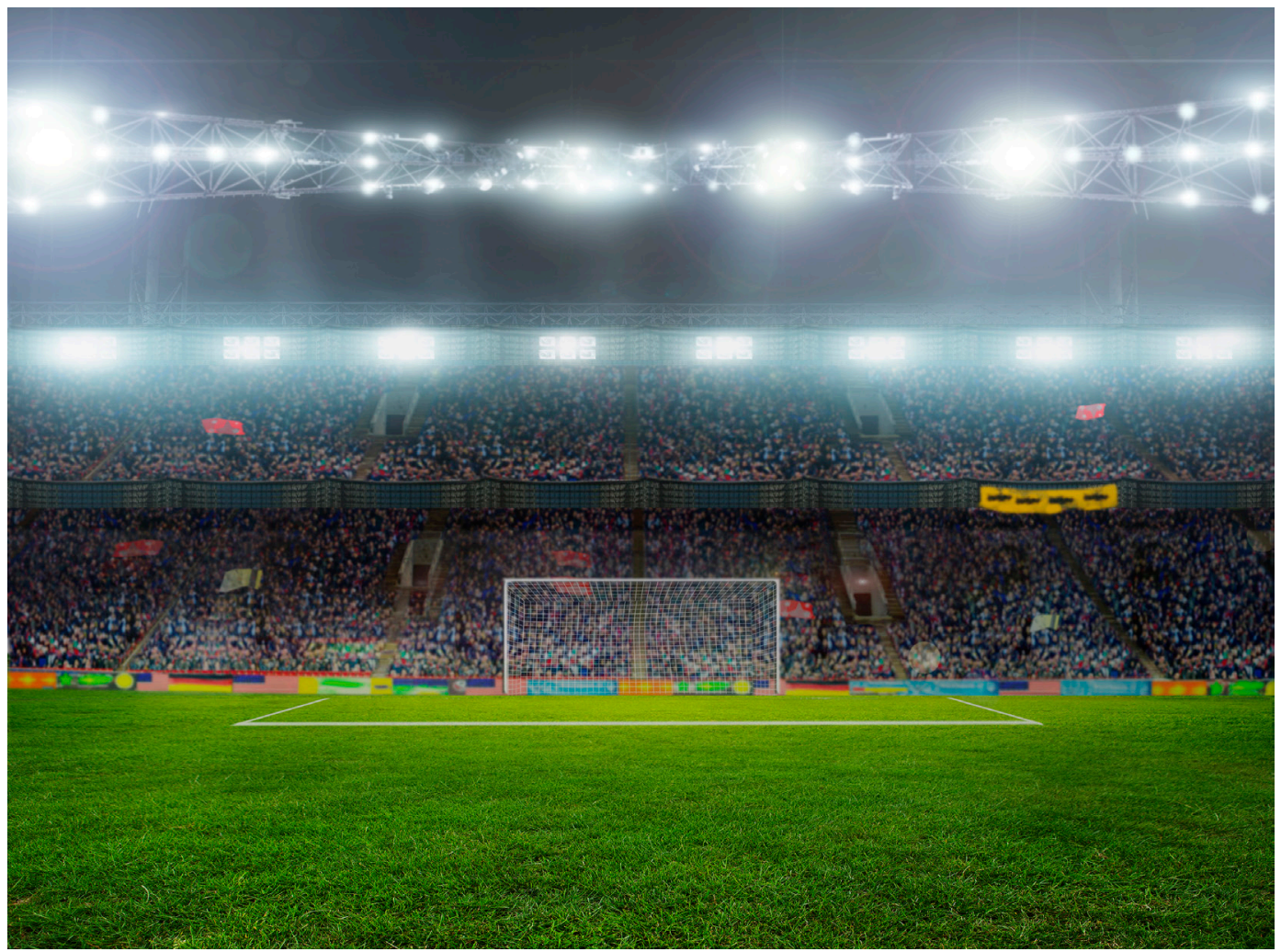


chance to win the championship, while a weak relationship between attendance and possibilities to qualify for the Champions League was found. While some clubs fight for championships, others fight for survival. Relegation presumably hurts the pride of a team's supporters and is associated with lower ticket prices as well as lower TV revenues. The possibility of relegation and the aversion towards it constitutes another argument for the opposition to high UO. Coates et al. (2014) provides a theoretical framework incorporating loss aversion among home team fans, which would motivate the rejection of the UO hypothesis. Their model further explains home fans' interests in seeing upsets (where the away team is a huge favourite resulting in a low UO), which would motivate the rejection of the UO hypothesis as well.

As mentioned, previous studies of European football have yielded mixed results regarding the UO hypothesis. These studies have differed in many ways, including the number of seasons investigated (and the years investigated), the choice of explanatory variables, the model specifications and the choice of uncertainty measure. Our study is the first to find consistent evidence against the traditional UO hypothesis across the major leagues in Europe in a comparative study using the same variables, seasons and model specifications across all four leagues. Our results support the empirical findings by Forrest and Simmons (2006), Buraimo (2008) and Czarnitzki and Stadtmann (2002) and recent theoretical literature in the field (Coates et al., 2014). The study provides compelling evidence that the UO hypothesis on attendance demand can be rejected in European football.

It is uncertain whether the rejection of the UO hypothesis is transferable to other football leagues and other sports in general. If the risk of relegation and the opportunity of promotion contribute to explaining the results, we would expect similar results in other European football leagues and possibly in football leagues with similar league structures around the world as well. Pawlowski and Nalbantis (2015) comes to similar conclusions in Austria and Switzerland, as do Martins and Cró (2018) in their study of Portuguese football, while Watanabe (2012) finds support of the UO hypothesis in a study of Japanese football which has a league structure similar to European football. However, only seasonal uncertainty was investigated, rendering direct comparisons difficult. More research on this is clearly warranted.

As in all studies, our model is limited on the number of variables, as many factors might influence spectators' choices. One factor could be the weather conditions at the beginning of the game (Garcia and Rodriguez, 2002; Czarnitzki and Stadtmann, 2002). Another variable often used indicates whether a game was televised live (e.g. Forrest and Simmons, 2006; Martins and Cró, 2018). The idea is that a live televised game will act as a substitute for the spectators in the stadium. Previously it has not been possible for supporters to watch all games live on TV, as only a few games per week were broadcast. However, with the internet it is now 
possible to watch all games in the four leagues live from your couch regardless of time and day of the week. It should be considered whether including TV/internet as a substitute is worthwhile. Finally, it seems natural that ticket prices have an impact on demand (Garcia and Rodriguez, 2002; Martins and Cró, 2018). Prices are however not easily obtained, and clubs usually differentiate prices according to opposition (higher prices against higher profiled teams) and seating positioning on the stadium. It is thus extremely difficult to infer the different prices in the model. Importantly, however, Krautmann and Berri (2007) have shown that ticket price is not a major determinant of attendance in sports, since sporting tickets (including football tickets) are regularly priced in the inelastic range of demand. For omitted variable bias to be a significant threat to the conclusions of this paper, the omitted variables should influence Theil's measure. There are no immediate reasons to believe that this would be the case. In the random effects tobit model, we assume that variation across teams is random and uncorrelated with Theil's measure. There are also no reasons to believe that this should not be the case. Moreover, it is reasonable to assume that differences across teams influence the number of attendees. This makes a random effects model appropriate. Finally, as tobit is a non-linear function, the likelihood estimator for fixed effects is biased and inconsistent. As a robustness check we ran fixed effects OLS regression models for all four leagues. When not taking account of censoring, the coefficient for Theil's measure was negative and significant for all four leagues. Hence, importantly, conclusions remained the same across models.

\section{CONCLUSION}

We conclude that the UO hypothesis is rejected in the four largest European football leagues. Moreover, attendees in the Spanish La Liga and the Italian Serie A prefer matches with a lower level of uncertainty. Previous studies have focused on single countries (except for Pawlowski and Nalbantis, 2015) and have used different measures of UO as well as different econometric models. This study has the advantage of being consistent in the use of UO measure, explanatory variables and econometric model across countries and across seasons. This is to date the most compelling evidence that the UO hypothesis on attendance demand does not hold in European football. 


\section{REFERENCES}

Borland, J., and Macdonald, R. (2003). Demand for sport. Oxford Review of Economic Policy, 19(4), 478-502. DOI 10.1093/oxrep/19.4.478

Buraimo, B. (2008). Stadium Attendance and Television Audience Demand in English League Football. Managerial and Decision Economics, 29, 513-523. DOI 10.1002/ mde.1421

Buraimo, B., and Simmons, R. (2008). Do sports fans really value uncertainty of outcome? Evidence from the English Premier League. International Journal of Sport Finance, 3(3), 146-155.

Cairns, J., Jennett, N., and Sloane, P. J. (1986). The Economics of Professional Team Sports: A Survey of Theory and Evidence. Journal of Economic Studies, 13(1), 3-80. DOI 10.1108/eboo2618

Coates, D., Humphreys, B. R., and Zhou, L. I. (2014). Reference-Dependent Preferences, Loss Aversion, and Live Game Attendance. Economic Inquiry, 52(3), 959-973. DOI 10.1111/ecin.12061

Czarnitzki, D., and Stadtmann, G. (2002). Uncertainty of outcome versus reputation: Empirical evidence for the First German Football Division. Empirical Economics, 27(1), 101-112. DOI 10.1007/s181-002-8361-7

Falter, J., and Perignon, C. (2000). Demand for football and intramatch winning probability: an essay on the glorious uncertainty of sports. Applied Economics, 32(13), 1757-1765. DOI 10.1080/000368400421101

Forrest, D., and Simmons, R. (2006). New issues in attendance demand: The case of the English Football League. Journal of Sports Economics, 7(3), 247-266. DOI $10.1177 / 1527002504273392$

Forrest, D., and Simmons, R. (2002). Outcome uncertainty and attendance demand in sport: The case of English soccer. The Statistician, 51(2), 229-241. DOI 10.1111/14679884.00314

Garcia, J., and Rodriguez, P. (2002). The determinants of football match attendance revisited: Empirical evidence from the Spanish Football League. Journal of Sports Economics, 3(1), 18-38. DOI 10.1177/152700250200300103

Greene, W. H. (1997). Econometric Analysis. Upper Saddle River, New Jersey: Prentice-Hall.

Kahneman, D., and Tversky, A. (1979). Prospect Theory: An Analysis of Decision under Risk. Econometrica: Journal of the Econometric Society, 47(3), 263-291. DOI $10.2307 / 1914185$

Krautmann, A. C., and Berri, D. J. (2007). Can we find it at the concessions? Understanding price elasticity in professional sports. Journal of Sports Economics, 8(2), 183-191. DOI $10.1177 / 1527002505275093$ 
Martins, A. M., and Cró, S. (2018). The demand for football in Portugal: New insights on outcome uncertainty. Journal of Sports Economics, 19(4), 473-497. DOI 10.1177/1527002516661602

Neale, W. C. (1964). The peculiar economics of professional sports: A contribution to the theory of the firm in sporting competition and in market competition. The Quarterly Journal of Economics, 78(1), 1-14. DOI 10.2307/1880543

Pawlowski, T. (2013). Testing the uncertainty of outcome hypothesis in European professional football: A Stated Preferences Approach. Journal of Sports Economics, 14(4), 341-367. DOI 10.1177/1527002513496011

Pawlowski, T., and Anders, C. (2012). Stadium attendance in German professional football - the (un)importance of uncertainty of outcome reconsidered. Applied Economic Letters, 19(16), 1533-1556. DOI 10.1080/13504851.2011.639725

Pawlowski, T., and Nalbantis, G. (2015). Competition format , championship uncertainty and stadium attendance in European football - a small league perspective. Applied Economics, 47(38), 4128-4139. DOI 10.1080/00036846.2015.1023949

Rottenberg, S. (1956). The baseball players' labor market. Journal of Political Economy, 64(3), 242-258. DOI 10.1086/257790

Szymanski, S. (2003). The economic design of sporting contests. Journal of Economic Literature, 41(4), 1137-1187. DOI 10.1057/9780230274273

Watanabe, N. M. (2012). Japanese professional soccer attendance and the effects of regions, competitive balance, and rival franchises. International Journal of Sport Finance, 7(4), 309-323.

Photos: Colourbox 